\title{
Modelling and Optimization for a High Temperature Generator of Absorption Chiller
}

\author{
Su Kyoung Lee, Jin Taek Chung, Yong Tae Kang \\ School of Mechanical Engineering, Korea University \\ 145 Anam-ro, Seongbuk-gu, Seoul, Republic of Korea \\ tnrud6917@korea.ac.kr; jchung@korea.ac.kr; ytkang@korea.ac.kr
}

\section{Extended Abstract}

Since an absorption chiller can increase the gas consumption during the summer period, it is an efficient and complementary cooling system for national energy supply and demand. Double effect absorption chiller that has been widely used in current days has two generators (high temperature generator, low temperature generator). The objective of this study is to model the high temperature generator for $\mathrm{H}_{2} \mathrm{O} / \mathrm{LiBr}$ absorption chiller and to find the optimum conditions that result in the minimum size of the heat exchanger. The generator size is dependent on four variables of tube length $\left(\mathrm{L}_{\text {tube }}\right)$, tube diameter $\left(\mathrm{D}_{\text {tube }}\right)$, the number of tubes $\left(\mathrm{N}_{\text {tube }}\right)$ and curvature ratio( $\left(\mathrm{R}_{\text {curv }}\right)$. The optimum conditions are decided by an optimization algorithm and the whole process is executed in EES (Engineering Equation Solver) program.

In this study, the high temperature generator consists of a shell and curved tubes where high temperature steam passes through and the outside of the tubes is filled with $\mathrm{H}_{2} \mathrm{O} / \mathrm{LiBr}$ solution of low concentration. As the heat exchange occurs on the tube wall, the steam and $\mathrm{H}_{2} \mathrm{O} / \mathrm{LiBr}$ solution leave the heat exchanger as subcooled water and in high concentration of $\mathrm{LiBr}$, respectively. The Gnielinski's correlation [1] is used for modelling the single-phase flow in the tubes and the Shah's correlation [2] is used to model the condensing flow in the tubes. The Cornwell's correlation [3] is applied for the pool boiling of $\mathrm{H}_{2} \mathrm{O} / \mathrm{LiBr}$ inside the shell. As the refrigerant evaporates during the pool-boiling process, the saturation temperature changes according to the concentration change in the $\mathrm{H}_{2} \mathrm{O} / \mathrm{LiBr}$ side. The saturation temperature variation according to the frictional pressure drop in the tubes and the minor loss due to curves is also considered for the steam side $[4,5,6]$.

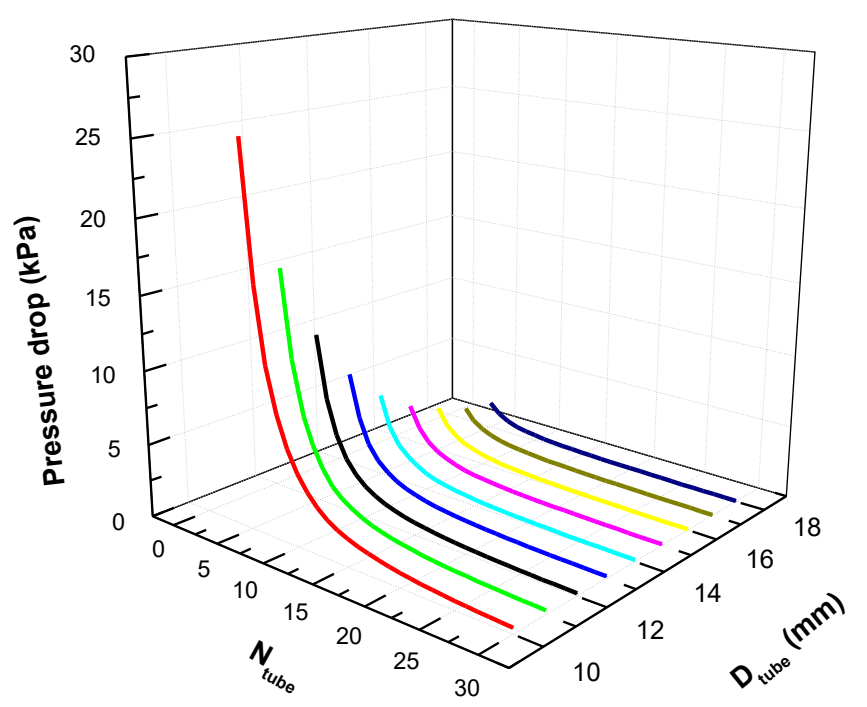

(a)

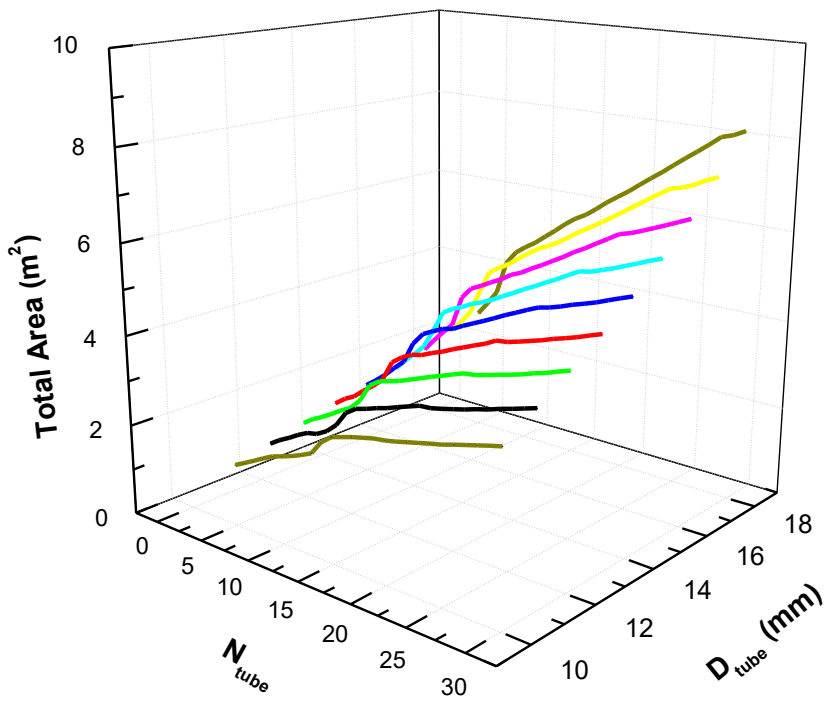

(b)

Fig. 1: Pressure drop and total heat transfer area according to the variations of $\mathrm{N}_{\text {tube }}$ and $\mathrm{D}_{\text {tube }}$. 
Fig. 1(a) shows the frictional pressure drop in tubes according to the variations of $\mathrm{N}_{\text {tube }}$ and $\mathrm{D}_{\text {tube }}$ of the high temperature generator. When $\mathrm{N}_{\text {tube }}>9$ the pressure drop becomes less than $1 \%$ of inlet pressure, which means the pressure drop can be neglected from this point. Fig. 1(b) shows the total heat transfer area according to the variations of $\mathrm{N}_{\text {tube }}$ and Dtube of the high temperature generator. The total heat transfer area increases with increasing $\mathrm{N}_{\text {tube }}$ and $\mathrm{D}_{\text {tube, which means }}$ that the heat transfer coefficient decreases for a given amount of heat transfer. From these results, an optimum combination of variables having a minimum size while satisfying the pressure drop constraint can be obtained.

This study proposes a novel modelling method for practical design of high temperature generator and provides the optimum conditions for the key parameters for the minimum volume of the generator.

\section{Acknowledgements}

This work was supported by the Korea Institute of Energy Technology Evaluation and Planning(KETEP) and the Ministry of Trade, Industry \& Energy(MOTIE) of the Republic of Korea (No. 20152010103060).

\section{References}

[1] V. Gnielinski, "New equations for heat and mass-transfer in turbulent pipe and channel flow," International chemical engineering, vol. 16, no. 2, pp. 359-368, 1976.

[2] M. M. Shah, "An improved and extended general correlation for heat transfer during condensation in plain tubes," Hvac\&R Research, vol. 15, no. 5, pp. 889-913, 2009.

[3] K. Cornwell and S. D. Houston, "Nucleate pool boiling on horizontal tubes: a convection-based correlation," International journal of heat and mass transfer, vol. 37, pp. 303-309, 1994.

[4] I. E. Idelshik, "Handbook of hydraulic resistance hemisphere," New York, 640, 1986.

[5] P. A. Domanski and C. J. Hermes, "An improved correlation for two-phase pressure drop of R-22 and R-410A in 180 return bends," Applied Thermal Engineering, vol. 28, no. 7, pp. 793-800, 2008.

[6] S. M. Kim and I. Mudawar, "Universal approach to predicting two-phase frictional pressure drop for adiabatic and condensing mini/micro-channel flows," International Journal of Heat and Mass Transfer, vol. 55, no. 11, pp. 32463261, 2012. 